\title{
Cold-induced activity of brown adipose tissue in young lean men of South-Asian and European origin
}

\author{
W. M. Admiraal • H. J. Verberne • F. A. Karamat • \\ M. R. Soeters • J. B. L. Hoekstra • F. Holleman
}

Received: 4 February 2013 / Accepted: 26 April 2013 /Published online: 25 June 2013

(C) Springer-Verlag Berlin Heidelberg 2013

\begin{abstract}
Aims/hypothesis South Asians have a disproportionately high risk of developing abdominal obesity, insulin resistance and type 2 diabetes. Brown adipose tissue (BAT) has been identified as a possible target to fight obesity and protect against metabolic disturbance. We explored whether lower BAT activity in South Asians compared with Europids may contribute to the high risk of metabolic disturbance.

Methods We studied 20 healthy men (ten Europids/ten South Asians, BMI 19-25 kg/m², age 18-32 years). Following $2 \mathrm{~h}$ of cold exposure $\left(16-18^{\circ} \mathrm{C}\right)$ after an overnight fast, ${ }^{18} \mathrm{~F}$-fluorodeoxyglucose $\left({ }^{18} \mathrm{~F}-\mathrm{FDG}\right)$ positronemission tomography-computed tomography (CT) and ${ }^{123} \mathrm{I}$-metaiodobenzylguanidine $\left({ }^{123} \mathrm{I}\right.$-MIBG) single-photon emission computed tomography-CT were performed to visualise metabolic BAT activity and sympathetic stimulation of BAT. Metabolic BAT activity was defined as maximal standardised uptake value $\left(\mathrm{SUV}_{\max }\right)$ of ${ }^{18} \mathrm{~F}-\mathrm{FDG}$, and sympathetic stimulation of BAT as semiquantitative
\end{abstract}

W. M. Admiraal $(\bowtie) \cdot$ J. B. L. Hoekstra $\cdot$ F. Holleman

Department of Internal Medicine F4-215,

Academic Medical Center, PO Box 22660,

1100DD Amsterdam, the Netherlands

e-mail: w.m.admiraal@amc.uva.nl

H. J. Verberne

Nuclear Medicine, Academic Medical Center,

Amsterdam, the Netherlands

F. A. Karamat

Vascular Medicine, Academic Medical Center,

Amsterdam, the Netherlands

M. R. Soeters

Endocrinology and Metabolism, Academic Medical Center,

Amsterdam, the Netherlands uptake value (SQUV) of ${ }^{123}$ I-MIBG. We performed hyperinsulinaemic-euglycaemic clamps to assess insulin sensitivity. Spearman's correlations for $\mathrm{SUV}_{\max }$ of ${ }^{18} \mathrm{~F}-\mathrm{FDG}$ and both SQUV of ${ }^{123} \mathrm{I}-\mathrm{MIBG}$ and insulin sensitivity were determined.

Results The median (interquartile range) $\mathrm{SUV}_{\max }$ of ${ }^{18} \mathrm{~F}$ FDG in South Asians (7.5 [2.2-10.6] g/ml) was not different from the median $\mathrm{SUV}_{\max }$ obtained in Europids (4.5 [2.2-8.4] $\mathrm{g} / \mathrm{ml} ; p=0.59$ ). There was no correlation between BAT activity and insulin sensitivity. Correlations between SQUV of ${ }^{123}$ I-MIBG and $\mathrm{SUV}_{\max }$ of ${ }^{18} \mathrm{~F}$-FDG were positive, both in the total population $(\rho=0.80, p<0.001)$ and after stratification by ethnicity (Europids, $\rho=0.65, p=0.04$; South Asians, $\rho=0.83, p=0.01$ ).

Conclusions/interpretation This is the first study to prospectively investigate ethnic differences in metabolic BAT activity during cold exposure. We did not find differences in BAT activity between South Asians and Europids. Therefore, it seems unlikely that BAT plays an important role in the development of unfavourable metabolic profiles in South Asians.

Keywords Brown adipose tissue $\cdot$ Ethnicity

$\begin{array}{ll}\text { Abbreviations } \\ \text { BAT } & \text { Brown adipose tissue } \\ \text { CT } & \text { Computed tomography } \\ { }^{18} \text { F-FDG } & { }^{18} \text { F-fluorodeoxyglucose } \\ \text { FPG } & \text { Fasting plasma glucose } \\ { }^{123} \text { I-MIBG } & { }^{123} \text { I-metaiodobenzylguanidine } \\ \text { IQR } & \text { Interquartile range } \\ \text { PET } & \text { Positron-emission tomography } \\ \text { ROI } & \text { Region of interest } \\ \text { SPECT } & \text { Single-photon emission computed tomography } \\ \text { SQUV } & \text { Semiquantitative uptake value }\end{array}$




$\begin{array}{ll}\text { SUV }_{\text {max }} & \text { Maximal standardised uptake value } \\ \text { SUV }_{\text {mean }} & \text { Mean standardised uptake value } \\ \text { VOI } & \text { Volume of interest }\end{array}$

\section{Introduction}

Several studies have shown that South Asians have a disproportionately high risk of developing abdominal obesity, insulin resistance and type 2 diabetes [1-4]. Next to the higher prevalence, these metabolic disturbances also seem to develop at an earlier age in South Asians than in populations of European origin. The explanation for these ethnic differences is complex and only partially clear $[3,5]$.

Given its high capacity to dissipate excess energy, brown adipose tissue (BAT) has recently been identified as a possible target to fight obesity and protect against metabolic disturbance [6-9]. As such, ethnic differences in BAT activity might be a contributing factor to the adverse metabolic profile in South-Asian people. So far, data on ethnic differences in the activity of BAT in humans are limited to one retrospective study that found no significant difference in the prevalence of BAT between white and black patients with cancer [10]. However, only a limited number of black patients were included in this study. Furthermore, as BAT is optimally visualised during cold exposure and the patients included in this retrospective study were not exposed to cold, only BAT detected incidentally was assessed [10]. Therefore, BAT, while present, may not have been detected in some of the patients, thereby masking true ethnic differences in BAT activity.

We aimed to explore whether a lower BAT activity in South Asians, in comparison with Europids, may contribute to this high risk of metabolic disturbance. In addition, we compared the insulin sensitivity and sympathetic stimulation of BAT, the latter being an important determinant of BAT activity, between South Asians and Europids.

\section{Methods}

We studied a group of 20 (ten Europid, ten South Asian) healthy, lean, male volunteers (age 18-32 years, BMI $19-25 \mathrm{~kg} / \mathrm{m}^{2}$ ). All the South-Asian men were Hindustani-Surinamese. The term 'Hindustani-Surinamese' refers to people of South-Asian ancestral origin and their offspring who migrated to the Netherlands via Surinam (a former colony of the Netherlands). The study participants were considered South Asian if both their parents, as well as their four grandparents, were of South-Asian origin. Nine out of the ten South-Asian participants were born in the Netherlands.
The study participants were recruited through public advertisements. All underwent a physical examination and a fasting blood sample was drawn. In order to determine the metabolic activity (i.e. glucose uptake) of BAT, the participants underwent ${ }^{18} \mathrm{~F}$-fluorodeoxyglucose $\left({ }^{18} \mathrm{~F}-\mathrm{FDG}\right)$ positron-emission tomography (PET)-computed tomography (CT). For the assessment of the sympathetic stimulation of BAT, a ${ }^{123}$ I-metaiodobenzylguanidine $\left({ }^{123} \mathrm{I}-\mathrm{MIBG}\right)$ single-photon emission computed tomography (SPECT)CT was performed. As two South Asians did not complete their last study visit (for reasons unrelated to the study protocol), ${ }^{123}$ I-MIBG SPECT-CT was performed in 18 of the 20 study participants.

Both ${ }^{18} \mathrm{~F}$-FDG and ${ }^{123} \mathrm{I}$-MIBG were administered after an overnight fast. The interval between ${ }^{18} \mathrm{~F}$-FDG PET-CT and ${ }^{123}$ I-MIBG SPECT-CT was set between 1 and 2 weeks. To overcome any order bias ${ }^{18} \mathrm{~F}$-FDG PET-CT and ${ }^{123} \mathrm{I}$-MIBG SPECT-CT were performed in random order. Furthermore, as healthy South Asians are less insulin sensitive than their European counterparts at a given BMI and age [11], and insulin sensitivity might influence BAT activity [12], we performed hyperinsulinaemic-euglycaemic clamps to assess insulin sensitivity in both ethnic groups. The institutional ethics committee of the Academic Medical Center approved the study protocol and all participants provided written informed consent.

Anthropometric and laboratory measurements Weight was recorded in light clothing on a SECA mechanical scale to the nearest $100 \mathrm{~g}$ (SECA, Hamburg, Germany). Height was recorded to the nearest $0.01 \mathrm{~m}$. Blood pressure was measured in seated position (Omron-M5-I, Omron Corporation, Kyoto, Japan). $\mathrm{HbA}_{1 \mathrm{c}}$ was measured by ion-exchange chromatography on a Tosoh-G8 analyser (Tosoh Bioscience, Tokyo, Japan). Levels of fasting plasma glucose (FPG), insulin (sandwich enzyme immunoassay; Roche Diagnostics, Rotzkreuz, Switzerland), total cholesterol, HDL-cholesterol, LDLcholesterol, triacylglycerol (enzymatic colorimetric method for all cholesterol and triacylglycerol measurements, Roche Diagnostics) and creatinine (colorimetric) were assessed.

${ }^{18}$ F-FDG PET-CT scanning protocol All participants were exposed to mild cold $\left(\sim 17^{\circ} \mathrm{C}\right.$, controlled by use of an air conditioning system) for the duration of $2 \mathrm{~h}$. Shivering was neither reported by participants nor noticed by research staff. After $1 \mathrm{~h}$ of cold exposure, approximately $200 \mathrm{MBq}$ of ${ }^{18}$ F-FDG was administered intravenously and the cold exposure was continued for another hour. Upper-body (from base of the skull to groin) static PET was performed $60 \mathrm{~min}$ after ${ }^{18}$ F-FDG injection.

PET-CT images were acquired using a Gemini time-offlight multidetector helical PET-CT scanner ( $2 \mathrm{~min} /$ bed position) (Philips Medical Systems, Eindhoven, the Netherlands). 
In areas where ${ }^{18} \mathrm{~F}$-FDG uptake was identified by PET and the presence of fat was identified by CT (Hounsfield units between -250 and -50 ), the mean standardised uptake value $\left(\mathrm{SUV}_{\text {mean }}\right)$ and the maximal standardised uptake value $\left(\mathrm{SUV}_{\max }\right)$, defined as activity $(\mathrm{Bq} / \mathrm{ml})$ within the region of interest $(\mathrm{ROI}) \div$ injected dose $(\mathrm{Bq} / \mathrm{g}$ body weight), were determined (Hybrid Viewer, Hermes Medical Solutions, Stockholm, Sweden). Anatomical ROIs were the cervical, supraclavicular and superior mediastinal depots. In these areas an SUV of ${ }^{18} \mathrm{~F}$-FDG of at least $2.0 \mathrm{~g} / \mathrm{ml}$ was considered to indicate BAT [6].

${ }^{123}$ I-MIBG-SPECT-CT scanning protocol All participants were pretreated with potassium iodide to block thyroid uptake of ${ }^{123} \mathrm{I}-\mathrm{MIBG}$. Again, the participants were exposed to mild cold for $2 \mathrm{~h}$. After $1 \mathrm{~h}$ of cold exposure, approximately $185 \mathrm{MBq}$ of ${ }^{123} \mathrm{I}$-MIBG was administered intravenously; exposure to cold was continued for another hour. The next day, $24 \mathrm{~h}$ after ${ }^{123}$ I-MIBG injection, a SPECT-CT scan was performed at the same anatomical region [13].

An Infinia SPECT-CT imaging system (General Electric, Fairfield, CT, USA) with a medium-energy all-purpose collimator and a $128 \times 128$ matrix was used to acquire SPECT images. A $15 \%$ window was set for the main energy peak of ${ }^{123} \mathrm{I}(159 \mathrm{keV})$. SPECT images were iteratively reconstructed (using ordered subset expectation maximisation) and corrected for attenuation using low-dose CT (no intravenous contrast). In areas where uptake of ${ }^{123}$ I-MIBG was identified by SPECT and the presence of fat was identified by $\mathrm{CT}$, both the mean and semiquantitative uptake of ${ }^{123}$ I-MIBG were calculated as, respectively, the mean or maximal (decay corrected) count per voxel in the volume of interest $(\mathrm{VOI}) \div$ mean count per voxel in a reference region (i.e. the mediastinum) (Hybrid Viewer) [13].

Alignment of ${ }^{18}$ F-FDG PET-CT and ${ }^{123}$ I-MIBG SPECT$C T$ The ${ }^{18} \mathrm{~F}$-FDG PET-CT and ${ }^{123}$ I-MIBG SPECT-CT were aligned using the $\mathrm{CT}$ images with Hybrid Viewer. The results of this automated non-rigid registration algorithm were visually validated. The specific VOIs on the anatomical images of ${ }^{18} \mathrm{~F}$-FDG PET-CT in which metabolically active BAT was present were copied to the aligned ${ }^{123}$ I-MIBG SPECT-CT images. Subsequently, the semiquantitative uptake of ${ }^{123}$ I-MIBG in these VOIs was calculated [13].

Hyperinsulinaemic-euglycaemic clamp The clamps were performed in the morning after an overnight fast. A cannula was inserted into the antecubital vein of the left arm. This cannula was used to infuse human soluble insulin (Actrapid; Novo Nordisk, Alphen aan den Rijn, the Netherlands) and $20 \% \mathrm{wt} / \mathrm{vol}$. dextrose. A second cannula was inserted into a vein on the dorsum of the right hand, which was placed into a heated hand box to arterialise the venous blood for blood sampling [14]. Infusion of human insulin was started at $1.5 \mathrm{mU} \mathrm{kg}^{-1} \mathrm{~min}^{-1}$, and $20 \%$ dextrose solution was infused at a variable rate to achieve a blood glucose concentration of $5.0 \mathrm{mmol} / \mathrm{l}$, which was maintained for $120 \mathrm{~min}$. Plasma glucose concentrations were measured every $5 \mathrm{~min}$ at the bedside. In the last $30 \mathrm{~min}$, blood samples were drawn at 10 min intervals for the measurement of insulin concentration. Insulin sensitivity was expressed as the mean glucose disposal rate $\left(\mathrm{mg} \mathrm{kg}^{-1} \mathrm{~min}^{-1}\right)$ during the last $30 \mathrm{~min}$ (i.e. the steady state) of the euglycaemic clamp.

Statistical analysis The characteristics of the study participants are reported as medians with interquartile range (IQR). The $p$ values for differences between South Asians and Europids in population characteristics, BAT volumes, SUV (mean and maximal) values of ${ }^{18} \mathrm{~F}-\mathrm{FDG}$, mean and maximal semiquantitative uptake value (SQUV) of ${ }^{123} \mathrm{I}-\mathrm{MIBG}$ and insulin sensitivity were determined with a Mann-Whitney $U$ test. Spearman's correlations between the $\mathrm{SUV}_{\max }$ of ${ }^{18} \mathrm{~F}-\mathrm{FDG}$ and both the SQUV of ${ }^{123} \mathrm{I}-\mathrm{MIBG}$ and insulin sensitivity were determined. Data analysis was performed using SPSS software 18.0 (Chicago, IL, USA). A $p$ value $<0.05$ was considered statistically significant.

\section{Results}

Table 1 shows the characteristics of our study population after stratification by ethnicity. Apart from a higher FPG and a lower HDL-cholesterol, the characteristics of the South Asians were similar to those of the Europids.

Both in the Europids and the South Asians, ${ }^{18} \mathrm{~F}-\mathrm{FDG}$ uptake in BAT was visually observed in eight out of ten male volunteers. Uptake of ${ }^{123} \mathrm{I}-\mathrm{MIBG}$ in BAT was observed in seven out of ten Europids, whereas six out of eight South Asians showed ${ }^{123}$ I-MIBG uptake in BAT (Fig. 1).

The median $\mathrm{SUV}_{\max }$ of ${ }^{18} \mathrm{~F}-\mathrm{FDG}$ (i.e. metabolic activity of BAT) was not significantly different between South Asians $(7.5[2.2-10.6] \mathrm{g} / \mathrm{ml})$ and Europids (4.5 [2.2-8.4] $\mathrm{g} / \mathrm{ml})(p=0.59$ [Table 1]). Furthermore, there were no ethnic differences in median $\mathrm{SUV}_{\text {mean }}$ of ${ }^{18} \mathrm{~F}-\mathrm{FDG}$ $(2.4 \mathrm{~g} / \mathrm{ml}$ in both groups) or in median BAT volume $\left(16.0\right.$ [5.5-64.5] $\mathrm{cm}^{3}$ in Europids, $38.4[8.4-59.3] \mathrm{cm}^{3}$ in South Asians; $p=0.57$ ).

In addition, we found no significant difference between the ethnic groups for either the mean or the maximal SQUV (i.e. sympathetic stimulation of BAT) of ${ }^{123} \mathrm{I}-\mathrm{MIBG}(p=0.26$ for the mean and $p=0.41$ for maximal SQUV of ${ }^{123}$ I-MIBG).

The correlation between the SQUV of ${ }^{123}$ I-MIBG and the $\mathrm{SUV}_{\max }$ of ${ }^{18} \mathrm{~F}$-FDG was positive, both in the total population $(\rho=0.80, p<0.001)$ and after stratification by ethnic group 
Table 1 Characteristics and BAT activity in the study population stratified by ethnicity
Data are presented as $n$ or median (IQR)

${ }^{\mathrm{a}}$ Presence of BAT was determined visually

${ }^{\mathrm{b}}$ Out of eight South Asians

${ }^{\mathrm{c}}$ During the last $30 \mathrm{~min}$ (steady state) of the hyperinsulinaemiceuglycaemic clamp

${ }^{*} p<0.05$ for differences between Europids and South Asians

TSH, thyroid-stimulating hormone

\begin{tabular}{|c|c|c|}
\hline Variable & Europids $(n=10)$ & South Asians $(n=10)$ \\
\hline \multicolumn{3}{|l|}{ Characteristic } \\
\hline Age (years) & $22.4(21.2-25.1)$ & $23.2(21.1-26.1)$ \\
\hline Height $(\mathrm{cm})$ & $181(180-185)$ & $174(170-178)^{*}$ \\
\hline Weight $(\mathrm{kg})$ & $72.3(67.4-79.4)$ & $65.5(63.0-71.9)$ \\
\hline $\operatorname{BMI}\left(\mathrm{kg} / \mathrm{m}^{2}\right)$ & $22.6(21.2-23.1)$ & $22.3(21.0-23.5)$ \\
\hline Waist circumference $(\mathrm{cm})$ & $79(76-82)$ & $79(74-82)$ \\
\hline Systolic blood pressure (mmHg) & $117(111-119)$ & $119(115-124)$ \\
\hline Diastolic blood pressure (mmHg) & $75(72-77)$ & $78(75-79)$ \\
\hline $\mathrm{HbA}_{1 \mathrm{c}}(\%)$ & $5.2(4.7-5.4)$ & $5.2(5.1-5.5)$ \\
\hline $\mathrm{HbA}_{1 \mathrm{c}}(\mathrm{mmol} / \mathrm{mol})$ & $33(28-36)$ & $33(32-37)$ \\
\hline Total cholesterol $(\mathrm{mmol} / \mathrm{l})$ & $3.63(3.52-3.96)$ & $4.12(3.38-5.02)$ \\
\hline HDL-cholesterol (mmol/l) & $1.56(1.44-1.78)$ & $1.45(0.84-1.49)^{*}$ \\
\hline LDL-cholesterol (mmol/l) & $1.86(1.76-2.23)$ & $2.25(1.83-3.33)$ \\
\hline Triacylglycerol (mmol/l) & $0.56(0.51-1.00)$ & $0.65(0.44-1.38)$ \\
\hline TSH (mU/l) & $2.6(1.9-4.5)$ & $2.75(1.6-5.1)$ \\
\hline Creatinine $(\mu \mathrm{mol} / 1)$ & $82(78-94)$ & 89 (79-97) \\
\hline \multicolumn{3}{|l|}{ Metabolic activity of BAT } \\
\hline Presence of BAT based on ${ }^{18}$ F-FDG PET-CT $(n)^{\mathrm{a}}$ & 8 & 8 \\
\hline $\mathrm{SUV}_{\max }$ of ${ }^{18} \mathrm{~F}-\mathrm{FDG}(\mathrm{g} / \mathrm{ml})$ & $4.5(2.2-8.4)$ & $7.5(2.2-10.6)$ \\
\hline $\mathrm{SUV}_{\text {mean }}$ of ${ }^{18} \mathrm{~F}-\mathrm{FDG}(\mathrm{g} / \mathrm{ml})$ & $2.4(1.6-3.3)$ & $2.4(1.5-3.2)$ \\
\hline BAT volume based on ${ }^{18} \mathrm{~F}$-FDG uptake $\left(\mathrm{cm}^{3}\right)$ & $16.0(5.5-64.5)$ & $38.4(8.4-59.3)$ \\
\hline \multicolumn{3}{|l|}{ Sympathetic stimulation of BAT } \\
\hline Presence of BAT based on $24 \mathrm{~h}{ }^{123}$ I-MIBG SPECT-CT $(n)^{\mathrm{a}}$ & 7 & $6^{\mathrm{b}}$ \\
\hline Maximal SQUV of ${ }^{123}$ I-MIBG & $3.1(2.3-3.9)$ & $3.9(2.2-5.0)$ \\
\hline Mean SQUV of ${ }^{123}$ I-MIBG & $4.0(3.0-5.7)$ & $4.7(4.3-6.1)$ \\
\hline BAT volume based on ${ }^{123}$ I-MIBG uptake $\left(\mathrm{cm}^{3}\right)$ & $16.7(6.2-52.6)$ & $36.3(7.0-59.9)$ \\
\hline \multicolumn{3}{|l|}{ Hyperinsulinaemic-euglycaemic clamp } \\
\hline FPG $(\mathrm{mmol} / \mathrm{l})$ & $4.6(4.4-4.9)$ & $5.1(4.7-5.2)^{*}$ \\
\hline Baseline insulin (pmol/l) & $<15(<15-28)$ & $47(<15-57)$ \\
\hline Steady-state glucose $(\mathrm{mmol} / \mathrm{l})$ & $5.0(4.9-5.1)$ & $5.0(4.9-5.0)$ \\
\hline Steady-state insulin (pmol/l) & $545(516-635)$ & $462(316-769)$ \\
\hline Glucose disposal rate $\left(\mathrm{mg} \mathrm{kg}^{-1} \mathrm{~min}^{-1}\right)^{\mathrm{c}}$ & $10.2(7.9-10.5)$ & $8.4(7.3-10.0)$ \\
\hline
\end{tabular}

(Europids: $\rho=0.65, p=0.04$; South Asians: $\rho=0.83, p=0.01$; Fig. 2).

The steady-state insulin levels of the Europids were similar to those of the South Asians (Table 1). There was no statistically significant difference in insulin sensitivity between the ethnic groups. Furthermore, there was no correlation between BAT activity and insulin sensitivity in the total population or after stratification by ethnicity (total group: $\rho=-0.10, p=0.68$; Europids: $\rho=0.04, p=0.91$; South Asians: $\rho=-0.14, p=0.73$ ).

\section{Discussion}

This is the first study that has prospectively investigated ethnic differences in metabolic BAT activity after cold exposure. We did not find differences in metabolic BAT activity or the sympathetic stimulation of BAT between South Asians and Europids. Therefore, it seems unlikely that BAT plays an important role in the development of the unfavourable metabolic profile in populations of South-Asian origin.

The ability to visualise metabolically active BAT in humans with ${ }^{18}$ F-FDG PET-CT under conditions of mild cold exposure has been reported in several studies [6, 8, 9, 15]. In our study, metabolically active BAT was found with ${ }^{18} \mathrm{~F}$-FDG PET-CT in $80 \%$ of all participants after $2 \mathrm{~h}$ of cold exposure $\left(16-18^{\circ} \mathrm{C}\right)$, which is in line with previous publications [8]. Furthermore, the median $\mathrm{SUV}_{\max }$ of ${ }^{18} \mathrm{~F}$-FDG in BAT is similar to values reported by Cypess et al, who also investigated BAT activity in lean, healthy men [16].

It is rather cumbersome to compare our data for $\mathrm{SUV}_{\text {mean }}$ and BAT volume with the results of other studies, as the 


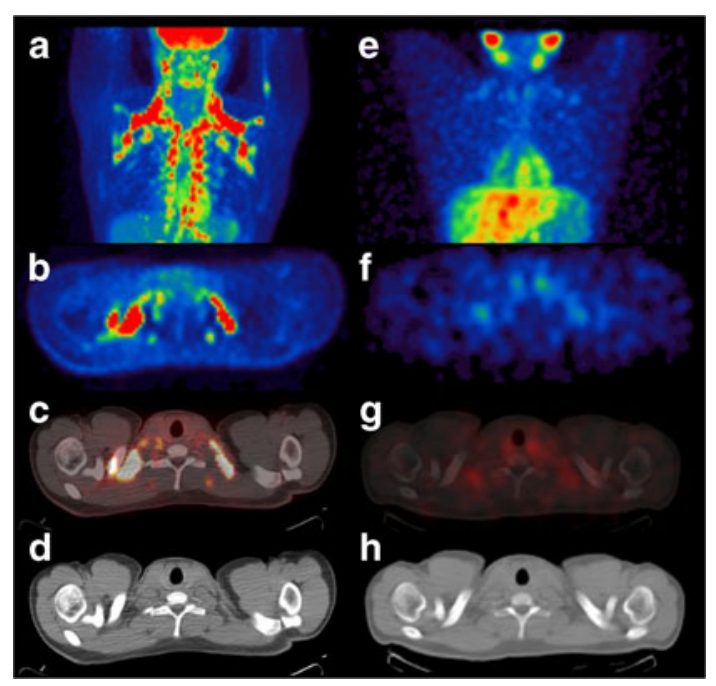

Fig. 1 (a, e) BAT in a South-Asian participant visualised with ${ }^{18} \mathrm{~F}$ FDG PET-CT and ${ }^{123}$ I-MIBG SPECT-CT (maximum-intensity-projection images). ${ }^{18} \mathrm{~F}$-FDG and ${ }^{123} \mathrm{I}-\mathrm{MIBG}$ uptake on corresponding transversal PET and SPECT images $(\mathbf{b}, \mathbf{f})$ is suggestive of BAT and is superimposed on adipose tissue on correlated transversal CT images (c, $\mathbf{d}$ and $\mathbf{g}, \mathbf{h}$, respectively)

$\mathrm{SUV}_{\text {mean }}$ and the derived BAT volume are largely dependent on the position and the definition of the ROI. As is to be expected in an emerging field of research, there is no consensus on the most appropriate way to define the ROI. In our study, a threshold for SUV of ${ }^{18} \mathrm{~F}-\mathrm{FDG}$ of at least $2.0 \mathrm{~g} / \mathrm{ml}$ was considered to indicate BAT (i.e. our ROI). Cypess et al used the same threshold [16]. However, Vosselman et al used a threshold of $1.5 \mathrm{~g} / \mathrm{ml}$ [17] and van Marken Lichtenbelt et al reported that they used a 'set threshold' [8], whereas Carey et al and Ouellet et al considered an SUV $>1.0 \mathrm{~g} / \mathrm{ml}$ as BAT $[18,19]$. The lower the chosen threshold, the higher the observed volume of BAT will be. For this reason, we cannot make direct comparisons between our results for $\mathrm{SUV}_{\text {mean }}$ and BAT volume and those of other studies.

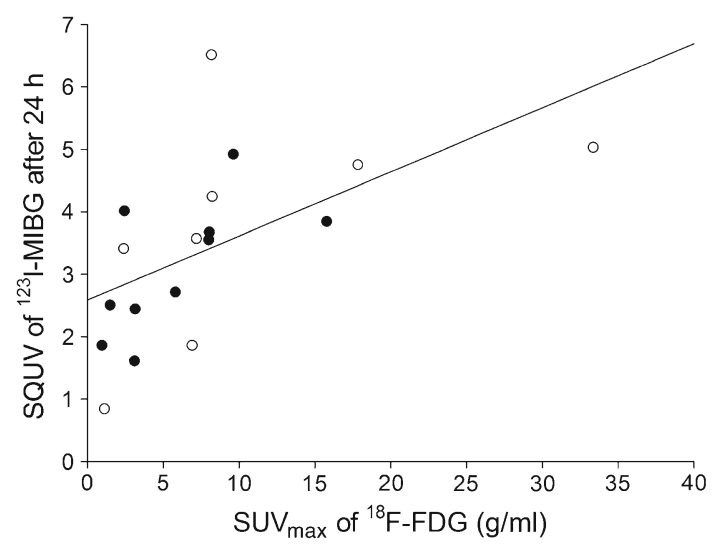

Fig. 2 The relationship between $\mathrm{SUV}_{\max }$ of ${ }^{18} \mathrm{~F}-\mathrm{FDG}$ and maximal SQUV of ${ }^{123}$ I-MIBG in Europids (black circles) and South Asians (white circles); Spearman's correlation coefficient $\rho=0.80, p<0.001$
The majority of the published studies on BAT activity have focused on individuals of European origin. However, there are data available on BAT activity after cold exposure in those with other ethnic backgrounds. For example, Saito et al studied BAT activity in Japanese men and women [15], whereas Miao et al focused on Chinese individuals [20]. It should be realised, however, that individuals of Chinese and Japanese origins have different metabolic constitutions from those of South-Asian origin. For example, Karter et al found that type 2 diabetes prevalence was much higher in South Asians than in Chinese, Japanese and other, unspecified, Asians [21]. Moreover, type 2 diabetes seems to develop at an earlier age and at lower levels of BMI in South Asians than in other populations [22]. For these reasons, we specifically focused on the BAT activity in South Asians in our study.

This is the first study that has prospectively compared BAT activity between ethnic groups. We found that the metabolic activity of BAT was not different between South Asians and Europids. We did not expect this finding, as both the tendency of South Asians to develop abdominal obesity and type 2 diabetes $[1,2,4]$ and the ontogenetic superfluity of the presence of BAT in the warm sub-Indian continent suggest BAT activity would be lower in South Asians than in Europids. As nine out of ten South Asians in our study were born in the Netherlands, it is unlikely that environmental factors influenced our results. Therefore, although surprising, our results suggest that the high risk of metabolic disturbance in South Asians, when compared with Europids, is not (partly) attributable to a relatively low BAT activity.

In line with the observed lack of ethnic difference in metabolic BAT activity, we did not find a difference in the sympathetic stimulation of BAT between the Europids and South Asians in our study. We previously validated ${ }^{123} \mathrm{I}$ MIBG SPECT-CT as a method to visualise and quantify the sympathetic stimulation of BAT in the ten Europid men who were also included in the present study [13]. In our previous study, we found that the correlation between the SQUV of ${ }^{123}$ I-MIBG and $\mathrm{SUV}_{\max }$ of ${ }^{18} \mathrm{~F}-\mathrm{FDG}$ was positive. The current finding of a positive correlation in South Asians in the present study corroborates our previous results.

Our study did not show a correlation between BAT activity and insulin sensitivity either in the total population or after stratification by ethnicity. Animal studies have shown that the BAT activity in both obese and insulinresistant mice is lower than in healthy mice [12]. Furthermore, obese people have a lower BAT activity compared with their lean peers [8]. In our study, all the individuals included were healthy and the absolute mean glucose disposal rates were within the expected range. Prospective follow-up studies are needed to determine how the correlation between BAT activity and insulin resistance develops over time. 
This study has limitations. Our sample size was small, so caution must be applied when extrapolating these results to the broader community. Furthermore, the limited number of participants may have resulted in a lack of power to demonstrate small differences between the ethnic groups. However, the mean $\mathrm{SUV}_{\max }$ of ${ }^{18} \mathrm{~F}-\mathrm{FDG}$ appeared higher in South Asians than in Europids. Therefore, it is unlikely that a greater sample size would alter our conclusion.

Furthermore, we did not perform a quantitative body-fat assessment in our study participants. For this reason, we cannot rule out the possibility that an ethnic difference in insulation, as a result of a difference in body-fat mass, has influenced our results on BAT activity. However, we did measure waist circumference and BMI, both of which have been shown to correlate well with total and regional measures of adiposity [23]. Given the low, lean values of BMI and waist circumference in both the South Asians and Europids in our study, it is not likely that the absolute difference in fat mass between the ethnic groups was great enough to have affected our results significantly. In addition, we used a room with a fixed temperature of $16-18^{\circ} \mathrm{C}$ to activate the BAT of our participants. This cooling method has been shown to be effective for the assessment of BAT activity in several other studies $[8,9,15]$. However, interindividual variation in the onset temperature of shivering has been reported, with some individuals starting to shiver at temperatures lower than $16-18^{\circ} \mathrm{C}$ [24]. As the thermogenesis of BAT is deemed to be at its highest just before the onset temperature of shivering [24], it is possible that BAT was not maximally activated in some of our study participants. As it is unknown whether the onset temperature of shivering differs between ethnic groups, it remains unclear whether our findings of a lack of ethnic differences in BAT activity were affected.

In conclusion, we found no difference in BAT activity during cold exposure between Europids and South Asians. Furthermore, we observed no ethnic differences in factors influencing BAT activity. Therefore, it seems unlikely that BAT plays an important role in the development of the unfavourable metabolic profile of populations of South-Asian origin.

Acknowledgement The results from this study were presented as an abstract at the ADA 73rd Scientific Sessions in June 2013.

Duality of interest All authors declare that there is no duality of interest associated with this manuscript.

Contribution statement WMA contributed to the design of the study, collected, analysed and interpreted the data and drafted the manuscript. HJV contributed to the design of the study, analysis of the data, and reviewed and edited the manuscript. FAK collected data, and reviewed and edited the manuscript. FH contributed to the design of the study and interpretation of data analysis, and reviewed and edited the manuscript. MRS contributed to the design of the study and reviewed and edited the manuscript. JBLH contributed to the design of the study and edited the manuscript. All of the authors approved the final version of the manuscript.

\section{References}

1. Chowdhury TA, Grace C, Kopelman PG (2003) Preventing diabetes in south Asians. BMJ 327:1059-1060

2. Gholap N, Davies M, Patel K, Sattar N, Khunti K (2011) Type 2 diabetes and cardiovascular disease in South Asians. Prim Care Diabetes 5:45-56

3. Oldroyd J, Banerjee M, Heald A, Cruickshank K (2005) Diabetes and ethnic minorities. Postgrad Med J 81:486-490

4. Samanta A, Burden AC, Fent B (1987) Comparative prevalence of non-insulin-dependent diabetes mellitus in Asian and white Caucasian adults. Diabetes Res Clin Pract 4:1-6

5. Whincup PH, Gilg JA, Papacosta O et al (2002) Early evidence of ethnic differences in cardiovascular risk: cross sectional comparison of British South Asian and white children. BMJ 324:635

6. Cypess AM, Lehman S, Williams G et al (2009) Identification and importance of brown adipose tissue in adult humans. N Engl J Med 360:1509-1517

7. Nedergaard J, Bengtsson T, Cannon B (2007) Unexpected evidence for active brown adipose tissue in adult humans. Am J Physiol Endocrinol Metab 293:E444-E452

8. van Marken Lichtenbelt WD, Vanhommerig JW, Smulders NM et al (2009) Cold-activated brown adipose tissue in healthy men. $\mathrm{N}$ Engl J Med 360:1500-1508

9. Virtanen KA, Lidell ME, Orava J et al (2009) Functional brown adipose tissue in healthy adults. N Engl J Med 360:1518-1525

10. Cronin CG, Prakash P, Daniels GH et al (2012) Brown fat at PET/ CT: correlation with patient characteristics. Radiology 263:836842

11. Raji A, Gerhard-Herman MD, Warren M et al (2004) Insulin resistance and vascular dysfunction in nondiabetic Asian Indians. J Clin Endocrinol Metab 89:3965-3972

12. Enerback S (2010) Human brown adipose tissue. Cell Metab $11: 248-252$

13. Admiraal WM, Holleman F, Bahler L, Soeters MR, Hoekstra JB, Verberne HJ (2013) Combining ${ }^{123}$ I-metaiodobenzylguanidine SPECT/CT and 18F-FDG PET/CT for the assessment of brown adipose tissue activity in humans during cold exposure. J Nucl Med 54:208-212

14. Abumrad NN, Rabin D, Diamond MP, Lacy WW (1981) Use of a heated superficial hand vein as an alternative site for the measurement of amino acid concentrations and for the study of glucose and alanine kinetics in man. Metabolism 30:936-940

15. Saito M, Okamatsu-Ogura Y, Matsushita M et al (2009) High incidence of metabolically active brown adipose tissue in healthy adult humans: effects of cold exposure and adiposity. Diabetes 58:1526-1531

16. Cypess AM, Chen YC, Sze C et al (2012) Cold but not sympathomimetics activates human brown adipose tissue in vivo. Proc Natl Acad Sci U S A 109:10001-10005

17. Vosselman MJ, van der Lans AA, Brans B et al (2012) Systemic $\beta$-adrenergic stimulation of thermogenesis is not accompanied by brown adipose tissue activity in humans. Diabetes 61:3106-3113

18. Carey AL, Formosa MF, van Every B et al (2013) Ephedrine activates brown adipose tissue in lean but not obese humans. Diabetologia 56:147-155

19. Ouellet V, Routhier-Labadie A, Bellemare W et al (2011) Outdoor temperature, age, sex, body mass index, and diabetic status determine the prevalence, mass, and glucose-uptake activity of 18FFDG-detected BAT in humans. J Clin Endocrinol Metab 96:192199

20. Miao Q, Zhao XL, Zhang QY et al (2012) Stability in brain glucose metabolism following brown adipose tissue inactivation in Chinese adults. AJNR Am J Neuroradiol 33:1464-1469 
21. Karter AJ, Schillinger D, Adams AS et al (2013) Elevated rates of diabetes in Pacific Islanders and Asian subgroups: the Diabetes Study of Northern California (DISTANCE). Diabetes Care 36:574-579

22. Mangalmurti SS, Paley A, Gany F, Fisher EA, Hochman JS (2010) South Asians and risk of cardiovascular disease: current insights and trends. Ethn Dis 20:474-478
23. Flegal KM, Shepherd JA, Looker AC et al (2009) Comparisons of percentage body fat, body mass index, waist circumference, and waist-stature ratio in adults. Am $\mathrm{J}$ Clin Nutr 89:500-508

24. Vijgen GH, Bouvy ND, Teule GJ, Brans B, Schrauwen P, van Marken Lichtenbelt WD (2011) Brown adipose tissue in morbidly obese subjects. PLoS One 6:e17247 